\title{
Расчет предпочтительной доходности пая при привлечении средств в рамках паевых фондов недвижимости
}

\author{
Распутин А.B. ${ }^{18}$
}

Одним из источников финансирования строчтельных проектов могут являться закрытыле паевые инвестиционныле фонды. С точки зрения инвесторов, такой источник является рискованным, поскольку определить результируюшую доходность до завершения проекта достаточно сложно. Для привлечения инвесторов предлагается устанавливать фиксированную ставку доходности по паям. Алгоритм расчета такой ставки рассмотрен 8 cmambe.

\section{JEL: $G 320$}

Ключевые слова: паевой фонд, источник финансирования строительного проекта

Ужесточение условий использования схемы долевого строительства и невысокая привлекательность вексельных схем привели к тому, что в 2005-2006 годах девелоперы начали поиск новой схемы привлечения средств для финансирования строительства жилых и коммерческих объектов. Мировой финансово-экономический кризис только подстегнул работу в этом направлении. При этом привлечение средств инвесторов и кредитных организаций стало серьезной проблемой в условиях ограниченного объема средств у последних и повышения рискованности вложений в недвижимость, а привлекать средства населения становилось все труднее в связи с потерей доверия к различным схемам, используемым застройщиками в прошлом.

Фактически за прошедшие пять лет на рынке появился только один новый способ привлечения денежных средств населения - формирование закрытых паевых инвестиционных фондов недвижимости.

Рассматривая закрытые фонды недвижимости как источник финансирования строительства, необходимо понимать, что в зависимости от момента привлечения средств отличаются и условия привлечения. К основным источникам привлечения средств до получения разрешения на строительство относятся собственные средства, средства стороннего инвестора (в основном для коммерческой недвижимости, а в случае с жилой это обычно бюджетные средства), облигационные займы и дополнительная эмиссия акций. После получения разрешения этот список расширяется за счет средств рынка (долевое строительство) и кредитных средств. Конструкция закрытого фонда может быть применена на любой стадии проекта, что очень важно, и зависит лишь от принципиальной позиции инвесторов, их отношения к риску.

Привлечение средств для возведения объектов жилой недвижимости через фонды может дать определенные бонусы застройщикам, которых нет у традиционного банковского кредитования строительства жилья. Однако механизм финансирования строительства через закрытые ПИФы недвижимости в итоге оказывается дороже традиционного банковского кредитования, которое в среднем в докризисный период обходилось в 10-15\% годовых, а сейчас доходит до $25 \%$.

При создании фонда недвижимости традиционная ставка доходности паев составляла 15-20\% годовых, если основным пайщиком является институциональный (так называемый квалифицированный) инвестор. На текущий момент требования данной категории инвесторов фактически не изменились, поскольку приоритет здесь отдается надежности

\footnotetext{
18 Аспирант, Байкальская международная бизнес-школа Иркутского государственного университета (БМБШ ИГУ).
} 
вложений. В случае же если основными вкладчиками являются частные инвесторы, приемлемый размер доходности для них составляет 20-25\% в год при приемлемых рисках.

Следует, однако, отметить, что параметры «риск» и «доходность» при оценке эффективности инвестиций в фонды недвижимости использовать не совсем корректно. Но по оценкам специалистов паи закрытых фондов недвижимости по шкале риска находятся между банковскими депозитами и финансовыми инструментами надежных эмитентов. Разные управляющие компании по своим различным проектам прогнозируют рублевую доходность от 12 до 40\% в год. Логично, что о работе фонда недвижимости корректно судить лишь после закрытия паев.

Это и является одной из основных причин низкой привлекательности закрытых фондов недвижимости для частных и небольшого количества существующих фондов, используемых для привлечения средств в целях жилищного строительства. Инвестор имеет только приблизительное понимание того, какой доходностью будут обладать вложенные средства, а информация о реальном положении дел может быть получена только после закрытия фонда. Кроме того, инвестор не может продать свой пай до завершения фонда.

Логичным решением было бы установление фиксированной ставки доходности по паям, по которой бы проводились предварительные выплаты, либо погашение пая до момента завершения фонда. Это позволило бы инвесторам в случае необходимости выйти из фонда до его закрытия и при этом сохранить и преумножить вложенные средства.

Тогда возникает другой вопрос: «Какую доходность устанавливать для пая?» Здесь автором предлагается использовать формулу, обратную применяемой для расчета средневзвешенной стоимости капитала.

Средневзвешенная стоимость капитала (Weighted Average Cost of Capital, WACC) является показателем, характеризующим стоимость капитала так же, как ставка банковского процента характеризует стоимость привлечения кредита. Отличие WACC от банковской ставки заключается в том, что этот показатель не подразумевает равномерных выплат, вместо этого требуется, чтобы суммарный приведенный доход инвестора был таким же, какой обеспечила бы равномерная выплата процентов по ставке, равной WACC.

Средневзвешенная стоимость капитала может быть рассчитана как:

$W A C C=W_{S} \times C_{S}+W_{D} \times C_{D} \times(100 \%-T)$,

где $\quad W_{S}$ - доля собственного капитала $(\%)$;

$W_{D}$ - доля заемного капитала $(\%)$;

$C_{\xi}$ - стоимость собственного капитала $(\%)$, или требуемая или ожидаемая доходность от собственного капитала (\%);

$C_{D}$ - стоимость заемного капитала $(\%)$, или требуемая или ожидаемая доходность от заемного капитала (\%);

$$
T \text { - ставка налога на прибыль (\%). }
$$

Это уравнение описывает ситуацию для однородных собственного и заемного капитала. Если в капитале присутствуют привилегированные акции со своей стоимостью, различные виды заемного капитала (каждый со своей стоимостью), то формула будет включать дополнительные слагаемые для каждого источника капитала.

Применительно к закрытым фондам расчет средневзвешенной стоимости капитала позволяет девелоперу, исходя из необходимой прибыльности деятельности, рассчитать допустимую доходность по паям при привлечении средств частных инвесторов в фонды недвижимости.

Так, в случае, когда источником финансирования жилищного строительства являются собственные средства и средства фонда, формула для расчета доходности пая (здесь стоимости заемного капитала) будет выглядеть так:

$$
\begin{aligned}
& C_{p}=\frac{W A C C-W_{s} \times C_{s}}{W_{D} \times(100 \%-T)^{r}} \\
& \text { где } \quad W_{p}-\text { доля средств, привлеченных с помощью фонда }(\%) ;
\end{aligned}
$$


$C_{p}$ - требуемая доходность пая $(\%)$.

В случае, когда используются иные источники заемного капитала (например, банковские кредиты), в формулу просто включаются дополнительные компоненты:

$$
C_{p}=\frac{W A C C-W_{S} \times C_{S}-\left(W_{D_{1}} \times C_{D_{1}}+\cdots+\left(W_{D_{n}} \times C_{D_{n}}\right) \times(100 \%-T)\right.}{W_{D} \times(100 \%-T)} .
$$

Расчет требуемой средневзвешенной стоимости капитала (WACC) при этом можно провести, исходя из данных о стоимости строительства, цены реализации и нормы прибыли, установленной компанией, либо исходя из требуемой доходности собственного капитала.

Рассмотрим пример, когда девелоперу для строительства 50-квартирного дома требуется 100 млн рублей. Объем собственных средств, которым он обладает, - 30 млн рублей; максимальный объем банковского кредита, который он может привлечь, - 40 млн рублей под 25\% годовых. На оставшуюся сумму застройщик планирует создать паевой фонд недвижимости. Ожидаемая доходность собственного капитала при вложении в альтернативный проект (банковский депозит) составляет $10 \%$, требуемая доходность собственного капитала при вложении в данный проект - 40\%, требуемая норма прибыли $15 \%$, превышение цены реализация над себестоимостью строительства - $50 \%$, а ставка налога на прибыль - 20\%. Длительность реализации проекта - 2 года. Рассчитаем предпочтительную доходность для пая с учетом требуемой нормы прибыли. Для этого сначала рассчитаем требуемую средневзвешенную стоимость капитала:

$W A C C=\sqrt{100 \%+50 \%-15 \%}-100 \%=16,19 \%$.

Тогда:

$C_{p}=\frac{16,19 \%-30 \% \times 10 \%-40 \% \times 25 \% \times(100 \%-20 \%)}{30 \% \times(100 \%-20 \%)}=21,63 \%$

С учетом требуемой доходности собственного капитала при вложении в данный проект:

$W A C C=\sqrt{100 \%+50 \%-40 \% \times 30 \%}-100 \%=17,47 \%$.

Тогда:

$$
C_{P}=\frac{17,47 \%-30 \% \times 10 \%-40 \% \times 25 \% \times(100 \%-20 \%)}{30 \% \times(100 \%-20 \%)}=26,96 \%
$$

В случае же, если застройщик отказывается от банковского кредита, предпочтительная доходность пая составит:

$$
\begin{aligned}
& C_{p}=\frac{16,19 \%-30 \% \times 10 \%}{70 \% \times(100 \%-20 \%)}=27,48 \% . \\
& C_{p}=\frac{17,47 \%-30 \% \times 10 \%}{70 \% \times(100 \%-20 \%)}=30,15 \% .
\end{aligned}
$$

В целом использование такого инструмента, как расчет средневзвешенной стоимости капитала, может предоставить обоснование не только для установления доходности пая при формировании фонда инвестиций, но и для оценки эффективности привлечения средств в рамках закрытого фонда, созданного на стандартных условиях (погашение пая по завершении фонда и т.д.). Однако использование данного метода связано с некоторыми допущениями (расчет требуемого WACC, прогнозирование цены и т.д.), что во многом ограничивает его применение.

Поэтому автор не предлагает использовать данный метод как панацею от всех бед, а лишь как один из возможных способов решения поставленной задачи.

\section{Список литературы}

1. Федеральный закон от 29 ноября 2001 года № 156-ФЗ «Об инвестиционных фондах».

2. Василенко Ю. Закрытые ПИФы недвижимости. [Электронный ресурс] // RealEstate.Ru: информационный портал о недвижимости. URL: http://www.realestate.ru/article.aspx?id=186 (дата обращения - 22 февраля 2010 года). 
3. Савчук В. Оценка эффективности инвестиционных проектов: Учебник [Электронный pecypc] // Корпоративный менеджмент: сайт. URLhttp://www.cfin.ru/finanalysis/savchuk/index.shtml (дата обращения - 22 февраля 2010 года). 